\title{
Older Female Caregivers and HIV/AIDS-Related Secondary Stigma in Rural South Africa
}

\author{
Catherine Ogunmefun • Leah Gilbert • Enid Schatz
}

Published online: 19 October 2010

(C) Springer Science+Business Media, LLC 2010

\begin{abstract}
South Africa's HIV/AIDS epidemic poses a major public health threat with multi-faceted harmful impacts and 'socially complex' outcomes. While some outcomes relate to structural issues, others stem from society's attitudinal milieu. Due to negative attitudes toward People Living with HIV/AIDS, stigmatisation mars their own experience and often extends to those close to them, in particular their caregivers. Many of the caregivers in South Africa are older women; thus, older women are the focus of this paper, which aims to examine HIV/AIDS-related stigma from their perspective. This paper explores secondary stigma as a socio-cultural impact of HIV/AIDS through repeated semistructured interviews with 60 women aged 50-75 in the MRC/Wits Rural Public Health and Health Transitions Unit research site (Agincourt), many of whom had cared for a family member with HIV/AIDS. Respondents' narratives reveal that many older persons
\end{abstract}

C. Ogunmefun

Demography and Population Programme, School of Social Sciences, University of the Witwatersrand, Johannesburg, South Africa

C. Ogunmefun

Health Systems Trust, Midrand, Johannesburg, South Africa

L. Gilbert $(\square)$

Department of Sociology, School of Social Sciences, University of the Witwatersrand, Private Bag 3, Johannesburg WITS 2050, South Africa

e-mail: leah.gilbert@wits.ac.za

E. Schatz

Department of Occupational Therapy \& Department of Women's \& Gender Studies, University of Missouri, Columbia, MO, USA

E. Schatz

Institute of Behavioral Science, University of Colorado, Boulder, CO, USA

E. Schatz

MRC/Wits Rural Public Health and Health Transitions Research Unit (Agincourt), School of Public Health, Faculty of Health Sciences, University of the Witwatersrand, Johannesburg, South Africa 
attribute high rates of death in their community to young persons' lack of respect for societal norms and traditions. The findings illustrate the forms and expressions of HIV/ AIDS-related secondary stigma and their impacts on older female caregivers. The types of secondary stigma experienced by the respondents include physical stigma in the form of isolation and separation from family members; social stigma in the form of voyeurism and social isolation; and verbal stigma in the form of being gossiped about, finger-pointing and jeering at them. Despite mixed reports about community responses toward infected and affected people, HIV/AIDS-related stigma remains a cause for concern, as evidenced by the reports of older women in this study.

Keywords Older women · Caregiving $\cdot$ HIV/AIDS $\cdot$ Secondary stigma $\cdot$ South Africa

Thandi $^{1}$ is a 63 year old woman who cared for her widower son when he returned from Johannesburg thin and ill. His four children ranging in ages 4-15 also returned with him. While he was ill, Thandi provided assistance with feeding, bathing and toileting, which entailed helping him to the pit latrine or emptying buckets of refuse from his room when he could no longer walk. She also travelled with him to seek medical care from the clinic, hospital and traditional healer, but nothing could prevent the inevitable. Her son's illness and death were troubling in a number of ways: she lost the income he had been remitting when he was working in Johannesburg; she had to take on the responsibility of raising his children; she had to use her pension money to pay for costs related to his illness, and later for funeral expenses. But, what worried and affected her most was how his illness and death brought shame on her and her household given its association with sexual taboos and prostitution, and she lost respect of her kin and neighbours due to stigma of the disease. Her grandchildren living elsewhere stopped visiting because there had been too much death in the household causing her to feel isolated and alone. She worried about why her neighbours came to visit, concerned that they were simply trying to gather information to spread through gossip. Although she knew that AIDS was common in her community, and that many people were more accepting of it now than in the past, she did not want people to know that her son had tested positive, or that she had used gloves when she bathed him, or that she herself worried about her own status. Her mental and physical health were negatively affected by how she perceived that others perceived her.

\section{Introduction}

The HIV/AIDS epidemic in South Africa poses a major public health threat associated with multi-faceted harmful impacts and 'socially complex' outcomes (Benatar 2004; Gilbert 2008). While some of these outcomes relate to structural issues, others stem from society's attitudinal milieu and its attempts to make sense of the disease (Madru 2003; Campbell et al. 2005; Yang et al. 2007). As reflected in the literature, many of the prevalent negative attitudes are fuelled by cultural or local beliefs about the disease and its causes (Parker and Aggleton 2003; Liddell et al. 2005; Ashfort and Nattrass 2005). As a consequence, the

\footnotetext{
${ }^{1}$ Thandi is a composite that represents the lives of many of our respondents who had experienced the loss of an adult child to AIDS, whether within or beyond their household. It highlights the experiences of secondary stigma brought on by this illness and death.
} 
experiences of People Living with HIV/AIDS (PLWHA) are often marred by stigmatisation from the wider society, their communities, and even their families (Castro and Farmer 2005; Gilbert and Walker 2010). In Goffman's (1963) terms, this makes them feel reduced from "normal" to "tainted" or "discounted" people and has a profound effect on their well-being (Cameron 2005; Simbayi et al. 2007). The stigma is often extended to those who are close to them, such as their family members, and in particular their caregivers (Deacon et al. 2005; Steinberg 2008).

Families face severe dilemmas in the context of extreme stigma. They are often condemned and stigmatised by virtue of their association with a family member who is HIV positive. Recent research in a rural area in the Mpumalanga Province of South Africa revealed that the stigma of AIDS, "leads families to banish children who are infected with AIDS; husbands chase away wives who have become sick with AIDS; everyday life is structured by strenuous regimes of public secrecy and disavowal of AIDS; priests are frightened to mention the subject of AIDS at funerals even when (and perhaps especially when) people know the cause of death" (Posel 2004: 23).

Drawing on Goffman's (1963) notion of "courtesy stigma" Walker (2007) argues that family members and partners of people living with HIV/AIDS have been "stigmatised by association". Walker (2007: 86) describes households with sick family members who were not willing to identify themselves openly: "The community was not accepting that family anymore because they were always talking that she's got AIDS and will pass it on to them and their children. The community hated them....."

It has been suggested that, as caregivers in particular, older women may experience stigma from their kin, neighbours and community due to their close physical contact with their patient (VanLandingham et al. 2005; Ogden and Nyblade 2005; Deacon et al. 2005). Some studies conducted in Africa and Asia revealed that older persons, who lost an adult child to HIV/AIDS, experienced different manifestations of secondary stigma such as gossip (Knodel and Saengtienchai 2002); name calling and rejection at the hands of community members (WHO 2002); loss of livelihood (Saengtienchai and Knodel 2001); and being held responsible for the "bad" behaviour of infected children (Ogden and Nyblade 2005). There is, however, little evidence in these studies about the underlying causes of HIV/AIDS-related stigma in the relevant settings. The paucity of research on this topic evokes the need for more empirical work on the ways social norms and cultural values connect with HIV/AIDS-related secondary stigma in the context of caregiving.

In South Africa, many of the caregivers are older women-mothers, aunts or grandmothers of those who are sick (Ferreira et al. 2001; Schatz and Ogunmefun 2007; Ogunmefun and Schatz 2009). This paper examines HIV/AIDS-related stigma from their perspective. Older women's roles are not limited to caregiving. The effects of stigma may extend to other relationships and roles within the family such as grandmothers and wives as well. This paper, thus, also turns attention to the implications of HIV/AIDS-related secondary stigma for older women's roles in the family.

\section{Data \& Methods}

The data analysed in this paper are part of a larger study, the Gogo Project (Schatz 2007; Schatz and Ogunmefun 2007; Ogunmefun 2008; Ogunmefun and Schatz 2009), which took place in the Medical Research Council (MRC)/Wits Rural Public Health and Health Transitions Unit (Agincourt) research site in rural Mpumalanga Province, South Africa. The 
interviews for this project were collected between July 2004 and February $2006 .^{2}$ The focus of the study is on the roles, responsibilities and kin relationships of women pre- and postpension eligibility, i.e., age 60 .

\section{Study context}

The Agincourt Unit has been conducting an annual census of households (births, deaths, in/ out migrations) since 1992. As of the 2008 census, the site was home to approximately 81,000 people, living in approximately 14,000 households in 25 villages. AIDS, as a cause of death, has steadily increased in the site since the mid-1990s. In 1992, just 1\% of all adult deaths were attributable to AIDS, by $2003,22 \%$ of adult deaths were attributable to AIDS (Madhavan and Schatz 2007). The antenatal HIV-prevalence in the province is upwards of $30 \%$ (SADOH 2006).

The Agincourt population has low levels of education and high rates of unemployment. There is little subsistence agriculture, but families do rely on small gardens for supplemental food. Post-apartheid, this area continues to be a sending area for temporary labour migrants to nearby towns and farther away cities. The primary language and ethnic group in the area is Shangaan, with little variation within the site. Multi-generational households, particularly those made up of women, their children and grandchildren are common. A unique feature of South Africa is the strong social grant system. This governmental program provides a non-contributory means-tested pension to all women and men over the age of 60 , as well as providing smaller but still meaningful child grants for children in poor households.

\section{Sample}

Agincourt census and verbal autopsy data (2001-2003) were used to produce a stratified random sample of households with and without a recent adult death from AIDS or other causes. The aim of this approach was to be able to assess whether older women's roles and responsibilities differed in households with and without a recent AIDS-related death. Onethird of the respondents in each phase of the study lived in households that had experienced an adult AIDS-related death between 2001 and 2003; one-third lived in households where an adult death due to another cause had occurred, and one-third in households with no adult death during the period. While households are the default unit of "family" due to the way the verbal autopsy and census data are collected, the interviews provide a lens into the experiences of older women and their connected kin beyond their households. Of the 60 women in the sample, 19 of them said they had acted as a caregiver to someone they knew or suspected was HIV positive.

\footnotetext{
${ }^{2}$ The Gogo Project began in July-September 2004 with repeated semi-structured interviews with 30 South African women aged 60-75. In October 2004-February 2005, the study added 30 women aged 60-75 of Mozambican descent living in the Agincourt site (Schatz 2009); these interviews are not included in the current analysis. Finally, in November 2005-February 2006, Ogunmefun further extended the study for her dissertation research adding 30 pre-pension eligible women aged 50-59 (Ogunmefun 2008). She also conducted follow-up interviews related to issues of stigma with the South Africans in the original Gogo Project sample-27 out of 30 women were re-interviewed; one had passed away, one refused to be interviewed and a third was mentally ill. See Schatz and Ogunmefun 2007, Ogunmefun 2008 and Ogunmefun and Schatz 2009 for an in depth discussion of sampling and response rates.
} 
Data collection

The principal investigator trained three local fieldworkers in qualitative interviewing techniques and on the content of the study. Each fieldworker interviewed one-third of the respondents thrice, recorded, transcribed and translated interviews into English (see Schatz and Ogunmefun 2007; Ogunmefun 2008 for a full discussion of fieldwork methods). At least three hour long in-depth semi-structured interviews were conducted with each of the 60 respondents. Topics in the interviews included the receipt and use of social grants, caregiving of orphaned and fostered children, and the sick (mainly adult children suffering from HIV/AIDS), and issues related to AIDS in their households and community, including stigma. [See appendix for questions directly related to stigma.] Although the stratified sample allows for a comparison of households in which there has been a recent HIV/AIDS death with those where there has not, there are strikingly few differences between the households in the three strata when it came to ideas about AIDS and stigma. Before interviews were conducted, the interviewers obtained informed verbal consent ${ }^{3}$ from the respondents and also informed them that they were permitted to withdraw at any point during the interview.

Data analysis

Data analysis began in the field with extensive investigator involvement. During the fieldwork, each interview transcript was reviewed to explore emergent themes or concepts, with new questions written to be investigated in later interviews. Making use of the constant comparative method helped not only in monitoring the outcome of each interview but also in making comparisons between data and concepts as well as in refining the interview guide in line with emergent themes (Oktay 2004). After completing the fieldwork, the authors continued to use an inductive approach to "ground" the analyses in the empirical world (Patton 1990: 67; Corbin and Strauss 1990; Neuman 2003).

The transcripts were imported to Nvivo; using an inductively created coding-tree of emergent themes, transcripts were coded at sentence or paragraph level. The coding-tree consisted of 38 axial codes, with about 250 sub-categories. This paper was based on analysis of "Reports" on axial codes related to caregiving, coping strategies, death and HIV/AIDS-related stigma.

\section{Results and Analysis}

It has been documented in various studies on HIV/AIDS-related stigma that infected and affected people often experience different forms of stigma from kin, friends and community members (UNAIDS 2000; Ogden and Nyblade 2005; Duffy 2005; Mahajan et al. 2008). This is the case in this study, where some of the respondents reported that they had similar experiences when a relative was sick or died of HIV/AIDS. Even those who had no relative that died of HIV/AIDS were able to describe the experiences of a family member, friend or neighbour that was infected or affected by the epidemic. It is widely acknowledged that the

\footnotetext{
${ }_{3}^{3}$ Verbal rather than written consent was used due to low levels of literacy among older persons in this community.
} 
forms and expressions of HIV/AIDS-related stigma experienced by HIV infected and affected individuals are embedded in the way a community views and responds to the epidemic (Ogden and Nyblade 2005; Ashfort and Nattrass 2005; Castro and Farmer 2005; Squire 2007). Thus, in order to understand older women's experiences of HIV/AIDSrelated stigma, respondents were asked to speak about community, family and personal responses to HIV/AIDS. Using narratives from the respondents, the sub-sections below focus on how community responds to those infected with HIV/AIDS, experiences of older women caring for HIV infected relatives and management of secondary stigma. In addition, perceived causes and beliefs about HIV/AIDS in the community as well as the consequences of secondary stigma are explored.

\section{Community responses to HIV/AIDS}

When asked about the general attitude of community members towards an HIV infected person, not surprisingly, the responses were mixed. The respondents reported both negative and positive attitudes towards PLWHA from members of the community. These findings echo those reported in Thailand where some participants reported negative reactions towards PLWHA and their parents, while some reported sympathetic and supportive reactions (Saengtienchai and Knodel 2001; Knodel and Saengtienchai 2002; VanLandingham et al. 2005).

According to a third of the respondents in this study, people in the Agincourt community do not show love to PLWHA and they gossip about and laugh at them. One of the respondents made an attempt to explain the reasons:

They don't show love to them, and gossip about them. They don't like to talk to them and the reason for this is that they don't want to be infected.

While another, although in agreement, had a different idea:

Community people will not show love to that person and they will gossip that the person is HIV positive because he/she is a prostitute.

These responses reveal and reflect some of the stereotypes about HIV/AIDS, namely irrational fear of transmission and assumptions about the moral integrity of PLWHA. Similar stereotypes were also reported in studies conducted in Ethiopia, Tanzania, Zambia and Vietnam (Ogden and Nyblade 2005). These public perceptions of stereotypes, in most cases, lead to negative attitudes and reactions towards people who are infected and affected by the epidemic.

In contrast to the above, thirteen of the respondents said that the community show love and treat HIV infected people like others in the community. According to one respondent:

[The] community people show love to the person because he/she didn't like to be HIV positive, it happened by mistake.

Although, in the minority, this kind of non-judgemental, positive attitude towards PLWHA is not unusual and was also reported in a study conducted in rural Malawi, in which, community members generally provided moral and social support for those who were infected and their caregivers. The study demonstrated that when questioned, the caregivers were reluctant to name AIDS as the disease, although they described its symptoms (Chimwaza and Watkins 2004). The non-identification of the condition, and therefore non-disclosure of the patient's status, might have contributed to the positive reaction from the community and eliminated the more common negative approach. 
Nearly one-third of the respondents said they do not know how the community responds to people who are infected. Some of them said they have no idea of what is happening in the community because they are old and some parts of their bodies are painful, making it difficult for them to move around. A few, however, said that it is hard to know how the community will react because people do not reveal their status. As explained by a respondent:

I don't know how [people react] because no one has exposed himself/herself by saying he/she is HIV positive so that we could see how the community reacts to him/ her.

Non-disclosure of status may, therefore, make it difficult to assess the reaction of people to HIV/AIDS. However, the mere fact that there is a need to keep HIV/AIDS a secret indicates that the expectations are that there would be a negative response from the community-therefore the avoidance strategy. Non-disclosure and the secrecy that surrounds HIV/AIDS, although meant to protect PLWHA and their caregivers, indirectly contribute to the prevailing negative attitudes and stigma as attested by others (Reid and Walker 2003; Cameron 2005; Campbell et al. 2005; Steinberg 2008).

Respondents' narratives, excerpted here, show that the attitude of community members towards HIV infected people could either be negative or positive in the Agincourt community. These mixed results are likely to extend to their close family members, especially their caregivers.

\section{Experiences of secondary stigma ${ }^{4}$}

Nearly all the respondents in this study were or are caregivers to adult children, spouses and other kin, some of whom were or are HIV positive (Schatz 2007). Of 60 respondents, 58 had taken care of at least one sick adult relative and of these 58 caregivers, 19 knew or suspected that their patient was HIV positive. When those who took care of an HIV infected relative were asked about their experiences of secondary stigma, some were able to relate their personal experiences, while a few said they never experienced stigma because they kept the status of their patient secret. The non-disclosure of the status of their patient, for these respondents, could be regarded as a symptom of "expected" or "anticipated" stigma. This has been reported in a study conducted among African-American caregivers in the USA (Poindexter and Linsk 1999) as well as other studies (Scambler 2004, 2006). The respondents who reported that they did not take care of an HIV infected relative were also asked about secondary stigma and some were able to relate the story of a relative or "a certain gogo (grandmother)" in their village who experienced what we would term secondary stigma.

In their study of HIV-related-stigma, Ogden and Nyblade (2005) referred to four main forms of stigma that HIV-positive people experience, that is, physical stigma - physical isolation and violence; social stigma-social isolation, loss of identity and voyeurism; verbal stigma - pointing fingers, taunting and rumours; and, institutional stigma-loss or inability to secure livelihoods, housing, health care or education. In order to find out whether older caregivers, who care for HIV positive people, also experienced these main forms of stigma, the respondents were asked questions relating to these types. Indeed, some of them reported that they experienced different forms of stigma that could be classified within these

\footnotetext{
${ }^{4}$ There is no word for stigma, or secondary stigma, in the local language; therefore, respondents were asked whether they experienced negative reaction as a result of caregiving for a sick loved one.
} 
categories, such as physical, social and verbal stigma. A respondent, who lost a son to HIV/ AIDS, was one of them. She described her experience:

...I will tell you about my experience with my son that died of AIDS. The community was gossiping and some were laughing at my family...Some of my friends were gossiping about me, that I would be infected because I was taking care of my son that died of AIDS. Some came to visit me in order to see what was happening in my house so that they could go around to gossip about me and my son... My husband is no longer sleeping with me. He said he doesn't want to be infected because I was the one taking care of my son who was HIV positive... I am sorrowful because I didn't choose to have a son who is HIV positive but I pray for them that God will open their eyes and make them to have feelings for those who are HIV positive.

Not only did she experience verbal stigma from community members when they gossiped about her and her family, but also social stigma from friends who visited in order to report to others in the community. She expressed lack of trust in the "people who come to visit"; this distrust suggests a sense of disconnection from friends and community members that may lead to feelings of isolation and rejection. In addition, she experienced isolation (physical stigma) from her spouse who refused to sleep with her due to fear of infection. This means that the caregiving role of some older women may affect their other roles, e.g. being a wife. There is no doubt that the loss of the role of wife is likely to have negative emotional and mental effects on the respondent.

Another respondent, who experienced verbal stigma from community members because of her brother-in-law's illness said:

I remember the time that my brother-in-law was sick with AIDS, people used to look at us in a bad way. Some said to me that they feel bad about my brother-inlaw's condition meanwhile they only wanted to gossip about him. And, sometimes when I was passing by, they pointed fingers at me to laugh and gossip... I was very worried.

Her lack of trust in people's concern for her illustrate that experiences of stigma may lead caregivers (and PLWHA) to doubt and question any gesture of social and moral support from friends and community members and, this is likely to lead to further isolation.

Although secondary stigma from community members and friends is very disturbing, it is that much more painful when it comes from close relatives. As recalled by one of the respondents who experienced stigma from her loved ones:

Because I was helping my sister to take care of her daughter who was HIV positive, my grandchildren keep on telling me that I must not cook anything for them because I may be HIV positive, because they don't want to be infected also...I am worried.

She admitted that she has never been to the clinic for a test because she did not think she contracted the virus, but she was very worried about the isolation (physical stigma) she has been experiencing from her grandchildren, which she perceived as an outcome of their fears that she had contracted the virus. This is not an isolated experience as can be seen from the testimony of a respondent who experienced physical stigma from her grandchildren. She said:

I did experience [stigma] as I told you that my grandchildren are no more visiting me. They say that they are afraid to die because three people have died here in my house; maybe I have something that kills people. Maybe they heard this from their parents. 
This respondent is a widow who lost a son and granddaughter that had symptoms similar to those of HIV/AIDS. In this community lack of contact with grandchildren is unusual; thus, stigma related to earlier caregiving of those who died of AIDS-related illnesses, affected her other role as a grandmother.

These results imply that the caregiving role of older women does not only lead to stigma but negatively impacts on their other gender roles within the family such as wives and grandmothers.

\section{Managing secondary stigma}

Although some respondents reported that they experienced secondary stigma from community members, friends and relatives, a few said they had no such experiences during or after caring for a loved one who died of HIV/AIDS. As evident in this respondent's report of the experience she had when her daughter died:

I was treated well, especially by people from the church. They used to come and pray

for me and the sick person... And [my family members] were very supportive.

The reason why this respondent (and a few others) said they never experienced secondary stigma may be due to the fact that they kept the status of their loved one secret because of the anticipated stigma, as mentioned earlier. The literature suggests that when stigma is anticipated or expected (also known as "felt stigma"), people sometimes find ways to manage it by concealing the status or condition (Goffman 1963; Poindexter and Linsk 1999; UNAIDS 2000; Campbell et al. 2005; Scambler 2006). Four of the respondents confessed that the reason that they did not experience stigma was because they did not disclose the HIV-status of their relative. Due to the prevalent migrant labour system in South Africa, this non-disclosure of status was easy in some cases as these caregivers' relative only came home shortly before passing away, which is the common practice (Clark et al. 2007). Others may have passed the symptoms off as those of tindzhaka. ${ }^{5}$ When caregivers anticipate stigma, they may manage it through non-disclosure of their patient's status. A study conducted in four townships in Western Cape, South Africa, also shows that due to stigma, some older caregivers concealed the disease, so that shame would not be brought on their household (Ferreira et al. 2001).

One of the respondents in our study explained why she had to manage the stigma she anticipated:

People in the community were good to me. They came in large numbers to mourn.

May be it is because my husband was a very kind man. Even during the funeral, people came in large numbers... I didn't experience any negative reaction because I didn't tell anyone that my husband was HIV positive. Even my parents and my husband's relatives did not know my secret... Dying of AIDS at that [time] was a secret. I think people would have gossiped about it and my husband's reputation would have been spoiled.

Her husband died in 2002 and she never told anyone (except her brother-in law) since then. During the interview she said:

Two years ago, people used to hate a person who is positive. They used to think that the person is infected because he/she is a prostitute. Nowadays, a person who is positive is loved by people. We feel sorry for him/her. We don't isolate him/her.

\footnotetext{
${ }^{5}$ Many in the Agincourt community believe that tindzhaka is another disease that has symptoms that are similar to those of HIV/AIDS; however, tindzhaka is caused by the breaking of taboos surrounding death and sex. Some of the taboos of tindzhaka are explained in narratives later in this paper.
} 
Although she expressed the belief that attitudes within the community may have changed such that people are more supportive of people with HIV and their families, she still kept her secret. Her actions suggest that she still felt that disclosure of the status of a loved one, even years after his/her death, can ruin the person's reputation and also lead to stigmatisation of those left behind. Since HIV/AIDS is a highly stigmatised disease especially where the major mode of transmission is through sexual intercourse, caregivers in this study tended to manage stigma by concealing the status of their patient. These caregivers perceived keeping the status of a loved one secret as a way to protect themselves from stigma and the shame of losing a relative to HIV/AIDS.

It seems that another way for people to shield themselves from shame is to ignore and deny the fact that their loved one died of HIV/AIDS. A study conducted in rural Uganda shows that denial of symptoms by a patient or family was common in the community (Muyinda et al. 1997). Family members of those who were infected kept repeating that they were alright or improving when the condition was actually deteriorating (Muyinda et al. 1997).

The responses of older caregivers, who are also family members of those who are infected with HIV/AIDS, may not be much different as they may also live in denial or ignorance of the fact that their patient is HIV positive. These older caregivers may find it easier to relate their experience by talking about a certain person that experienced it rather than referring to themselves. This may even make them feel safe as they do not want to be exposed to stigmatisation. Such responses were heard from four of the respondents in this study, who lost a relative to HIV/AIDS. These respondents reported that they took care of a loved one who died of symptoms that are similar to those of HIV/AIDS. However, when asked about their experience of secondary stigma, their response was negative, that is, they did not have such experience; but, they were able to talk about "a certain gogo (grandmother)" that experienced secondary stigma.

The response of an older woman, who took care of a daughter who had symptoms such as diarrhoea, sores and weight-loss suggesting she died of HIV/AIDS, illustrates the point made earlier. When asked whether she experienced secondary stigma because of taking care of her daughter, she replied that she did not experience any stigma because her daughter died of headaches. However, when asked whether she knew somebody else who experienced secondary stigma she said:

There was a certain gogo who was looking after her daughter who was HIV positive. She was treating her [daughter] well and they were sleeping together in the same room. She was cooking for her and also washing her. She was doing everything for her... People in the community were feeling sorry for the gogo and they visited the sick person. They also advised the gogo to take the sick person to the sangoma [traditional healer] to get muthi [traditional medicine]. Some gave the gogo muthi to give to the sick person, so this shows that the community loved this gogo.

Living in denial or talking about "a certain gogo" may make it easier for these older women to safeguard themselves from the shame or stigma associated with HIV/AIDS. Some may find it difficult to talk about their experiences of stigma, particularly with the interviewers who were members of their larger community, although not from their own village. One of the respondents refused to talk about her experience of secondary stigma when asked. She said:

I have told you that I know nothing about AIDS, so if you keep on asking me about it, I will keep quiet. 
This is despite the fact that the Agincourt verbal autopsy data revealed that someone had died from HIV/AIDS in her household in the period 2001-2003. Her complete denial of this knowledge and of the disease or stigma related to it could be as a result of fear of exposure to stigmatisation or other deep-rooted beliefs not explored in this study.

The above further underlines the complexity of people's response to HIV/AIDS. It also raises questions why some older caregivers may choose to ignore the disease and live in denial. In order to gain a more nuanced understanding of this phenomenon, there is a need to further explore the causes and beliefs underlying HIV/AIDS-related stigma in the Agincourt community - this is done in the following section.

Perceived causes and beliefs about HIV/AIDS and related stigma

As suggested in the literature on HIV/AIDS-related stigma (Ogden and Nyblade 2005; UNAIDS 2000; Mahajan et al. 2008), fear of infection is one of the prevailing factors responsible for the negative reactions towards HIV infected and affected people. According to Ogden and Nyblade (2005), the knowledge about the three correct modes of HIV transmission (sex, blood, and mother-to-child) sometimes co-exist with erroneous beliefs such as transmission through ordinary daily interactions with PLWHA. This irrational fear of transmission through every day contact, despite the knowledge that this is not the case, therefore, leads to stigma towards those who are infected and affected.

To better understand the forms and expression of secondary HIV/AIDS- related-stigma, respondents were asked about the causes of stigma in their community. The respondents confirmed the presence of the fear of transmission in their community, as demonstrated in this quote:

People are scared of HIV positive people because they think that they will be infected if they get close to the person, and others say that if you eat with them you may get infected.

Such erroneous ideas about HIV transmission may result in stigma towards those who are infected and affected. Another respondent gave an example by way of illustration:

People are scared that they will be infected by this disease. For example, if I am HIV positive and I give you food to eat, you won't eat it... You will be scared by the way I am looking because I will be thin with sores [on my body] and in the mouth. If I give food to you, you will refuse because you think that you will be infected.

This picture suggests that older women, and perhaps others, in this community understand HIV/AIDS like other communicable diseases that can be spread by contact with those who are infected. Regardless of the fact that some of the respondents are aware that the major mode of transmission of HIV is through unprotected sex, transmission by contact still dominates their minds. This is demonstrated in the following response:

Everyone is afraid of HIV/AIDS. People think if [an infected person] comes near you, you would be infected... We are told that it comes through sex but we don't [really] believe [it].

This means that the fear of transmission may still persist in people's minds despite extensive information, education and communication (IEC) programmes about HIV/AIDS (McDonald and Schatz 2006). This, according to Ogden and Nyblade (2005), may be due to the fact that HIV/AIDS messages rarely focus on explaining how HIV is not transmitted 
but on how HIV is transmitted and is incurable. This tends to further fuel the stigmatisation of HIV/AIDS in the society.

Assumptions about the moral integrity of people infected with HIV/AIDS, like fear of transmission, could also contribute to the stigma towards the infected and affected people (Ogden and Nyblade 2005). This is because sexually transmitted diseases "carry a moralistic judgment of blame", supposedly due to the indecent or promiscuous behaviour of the infected person (Madru 2003; Zhou 2007). As a result, the infected person is held responsible for contracting the illness and therefore stigmatised (Madru 2003). This is often extended to his/her caregivers as well. The link between HIV and morality could also be related to the fact that affliction is often discerned as a physical manifestation of a moral transgression or breaking of social prohibitions or taboos (Ogden and Nyblade 2005). The society therefore believes the culprit deserves the judgment of the disease - in this case HIV/AIDS.

These examples draw attention to the socio-cultural impact of HIV/AIDS. In a rural setting, local cultural beliefs and explanations about illness and disease causation can contribute to HIV/AIDS related stigma (Parker and Aggleton 2003). This associated stigma is likely to be transferred to older women who are caregivers to an infected child. In order to explore this phenomenon, the respondents were asked about the traditional beliefs about HIV/AIDS and stigma in the community. In their narratives, nearly all of the respondents insisted that the high prevalence rates of HIV/AIDS in the community are due to the fact that young people today no longer obey the norms and traditions of their society. This belief underlies the erroneous popular explanation of how HIV is transmitted in the community. A respondent had this to say:

The belief is that the young ones, mostly under the age of 18 , should not have sex but because this belief is not respected by them, they are infected by AIDS. The youth are not obeying the norms and values of the society, so many different diseases like AIDS and TB are at a high [prevalence] level.

The perception that HIV infection is the product of a bad personal behavioural choice, may impact on the community's assumption that the person ought to carry the blame if HIV infection ensues (Ogden and Nyblade 2005). In addition, it generates stigma from the community towards PLWHA if long-standing cultural traditions are broken in the process of making the personal choice that caused HIV infection; this stigma is later extended to affected kin. As noted earlier, a number of respondents made comments like the one below:

Community people will not show love to that person and they will gossip that the person is HIV positive because he/she is promiscuous.

Another study conducted in the same community (Agincourt) similarly showed that stigma is related to the belief that HIV/AIDS is transmitted by those who engage in "bad sex" (promiscuity) in the community and therefore, death from the disease is a just reward for their behaviour (Posel 2004). This provides further evidence that if a community believes that traditions are being broken because of people's sexual behaviour, they are unlikely to show empathy towards the infected person, and this could result in stigma towards the "offender" and those associated with them.

Another respondent who believed that the high death rate is due to the disobedience of the youth, however, cited a taboo as an example of the tradition that has been broken:

AIDS is caused by the young ones who never listen to their parents when they tell them about the norms and values of our culture. For example, if there is a death in our 
family and we eat food, we are not allowed to have sex until 7 days [pass]. But you will discover that they eat food in the afternoon and have sex with their partners at night, so this causes tindzhaka disease that is similar to AIDS.

Like her, many of the respondents believed that breaking of the "taboo of tindzhaka" is the reason why many are dying of HIV/AIDS in the community. Taboos reflect attempts to maintain order and protect against disaster in traditional societies (Madru 2003). Thus, local beliefs about the cause of HIV, such as youth disobeying the norms and traditions of the society and people breaking taboos, are likely to underpin the stigma in the community.

It has been suggested that stigmatisation may also be due to the fact that people in many societies tend to believe in karma, a way of making sense of cause and effect, which is expressed in the Bible as "What a man sows so shall he reap" (Ogden and Nyblade 2005). This, therefore, makes community members react negatively towards PLWHA and sometimes, the affected. When one of the respondents was asked whether she knew an older woman who experienced stigma as a result of taking care of an infected person, she said:

My neighbour died last month, towards the end of December, and people gossiped that she was HIV positive. Her mother [who cared for her] also became ill and now she has died. People said that the mother was also HIV positive. As you can see that there is nobody going to mourn in their house. Maybe they are scared that the person was HIV positive. Since morning, no one has gone to their house, even the pastor did not come to do the devotion. After her husband died some years ago, she started running around with men, telling people that she is not old. Today, she has died of AIDS and people didn't come to her house, and the few others that went there to mourn were grumbling that she became a prostitute when her husband died.

Although it is not clear from this narrative whether it was the daughter or mother that was promiscuous, it does show that stigma could be extended from the infected person to the caregiver, even after the person dies. As mentioned earlier, this is because some people believe that the infected person deserved the punishment due to his/her actions.

\section{Consequences of stigma}

There is no doubt that a complex association exists between HIV/AIDS primary and secondary stigma and the way both manifest themselves in a community. It is clear that stigma towards PLWHA translates into consequences for secondary stigma towards those associated with them and the qualities of the experiences of secondary stigma often mirror primary stigma.

Some respondents in this study believed that stigma could make PLWHA suffer loneliness as they isolate themselves or feel isolated:

They don't enjoy life anymore, and they feel that they are not welcomed in the community. They isolate themselves and think that it is better to die.

As both of them explained, the loneliness and depression related to an HIV/AIDS diagnosis and resulting stigma may even lead some to commit suicide. In order to elaborate on this, a respondent recalled a story about a suicide in her response:

They are not happy about it because they could see that people don't show love towards them, so some shoot themselves to death to commit suicide. I remember one 
boy committed suicide because nurses told him that he was HIV positive. He excused [himself] at night by telling his wife that he was going to the toilet, and [because] he was naked, his wife thought that he was really going to the toilet. Later they found him dead on the veld the following day.

This narrative shows that stigma towards PLWHA may make individuals contemplate suicide as a way out of the problem; especially if the person feel lonely, depressed, and rejected by the community. This may also further exacerbate the situation and make others conceal an individual's status to avoid rejection and lack of empathy from others in the community.

Like those who are infected with HIV/AIDS, affected people such as the older caregivers, can suffer loneliness, feel or be isolated by friends and the community because:

People don't want to visit the family as they are afraid of the disease, and they think that they will be infected if they visit the family.

The reluctance of community members to visit the family of an infected person is also due to the erroneous knowledge about the mode of transmission of the disease that is prevalent in this community, as discussed earlier.

The associated stigma, in addition to loneliness and isolation, may have more tangible negative outcomes. Some of the affected, especially caregivers, may lose their source of livelihood as a result. As one respondent commented:

"[The] family will have a problem if they have a business as people will no longer buy from them".

One of the respondents who lost a child to HIV/AIDS had this experience:

Like me, I sell traditional beer, so three months after the death of my daughter, the number of people who came to buy traditional beer decreased. But it is okay now and they are coming in large numbers like before.

Although she was fortunate to have her customers return, some affected people may be less fortunate. In a study conducted in Thailand, Saengtienchai and Knodel (2001) found that some caregivers had to quit or change to other types of work because of stigma.

These findings provide evidence that secondary stigma can have serious negative consequences for those who are affected, like some of the older women in this study. The implication of this is that HIV/AIDS-related secondary stigma may have long-term effect on older caregivers, especially in relation to their livelihood.

\section{Discussion \& Conclusion}

This paper explores they ways in which secondary stigma impacts older women and their experience of HIV/AIDS in their community. Respondents' narratives reveal that many attribute the high rate of adult death in their community to the fact that young people no longer respect the norms and traditions of their society, e.g. they no longer obey the "taboo of tindzhaka". Such beliefs seem to fuel HIV/AIDS stigma towards PLWHA and also older women who are their caregivers, thereby suggesting that secondary stigma could be rooted at least in part in cultural beliefs. 
Furthermore, findings illustrate the forms and expressions of HIV/AIDS-related secondary stigma in this rural community. The narratives show how secondary stigma impacts these older caregivers and how closely it mirrors primary stigma experienced by PLWHA. Despite the fact that there were mixed reports about the community responses towards infected and affected people, HIV/AIDS-related stigma is still a cause for concern, especially when it is experienced by older caregivers, like those in this study. There is evidence to suggest that their experiences of stigma extend beyond the community and family members to their own spouses and grandchildren. This means that they may be affected as older caregivers, as well as, wives, mothers and grandmothers. The types of secondary stigma reported by the respondents included physical stigma in the form of isolation and separation from family members; social stigma in the form of voyeurism and social isolation; and verbal stigma in the form of being gossiped about, finger-pointing and jeering at them.

Although some of the respondents said they had never experienced secondary stigma, findings demonstrated that this was, at least in part, due to non-disclosure of the status of the infected family member. In other words, some managed "anticipated" stigma through non-disclosure of their patient's status. As a result, some women were able to protect themselves from stigma and the shame of losing a loved one to HIV/AIDS. A few of the respondents also managed stigma by living in denial or ignorance of the status of their loved one. These respondents found it easier to talk hypothetically about "a certain gogo", while they might have talked about themselves. The implication of denial/non-disclosure is that the prevalence of HIV/AIDS-related secondary stigma, as HIV/AIDS infection, remains under-reported.

This study demonstrates that when older women take on caregiving roles, there may be knock-on negative effects on other gender roles such as being a wife and a grandmother. Since these other roles and relationships are central to the identity of older women, this is likely to compound the impact of HIV/AIDS on older women. However, not much has been written about it, hence the need for further research on this topic.

The potential loss of livelihood, following secondary stigma, is another issue worthy of further investigation, as it can compound the impact of HIV/AIDS by leading to a financial crisis. This makes the links between socio-cultural and economic impacts of HIV/AIDS that much more apparent. However, the inter-relation between these is beyond the scope of this paper.

The findings from this study are consistent with those from other studies (UNAIDS 2000; Posel 2004; Ogden and Nyblade 2005), as narratives show that fear of infection is one of the causes of HIV/AIDS related stigma in the Agincourt community. Regardless of existing popular knowledge about unprotected sex as the major mode of transmission in the community (McDonald and Schatz 2006), many still think of HIV as of any other communicable disease that can be contracted through casual contact, e.g. eating with and staying near PLWHA.

Based on this study, it is evident that as the epidemic progresses and more older women become caregivers to sick adult children, there is a growing need to address the issue of secondary stigma, just as primary stigma has come under spotlight in many HIV/AIDS intervention programmes. This is mainly because the stigma can make their caregiving responsibilities more burdensome as they try to cope with the loss itself, as well as, with the shame associated with the fact that their loved one died of HIV/AIDS. 


\section{Appendix}

\section{Selected questions/topics from interview guide related to primary and secondary AIDS-related stigma}

As you know more people are dying everyday, especially the young ones, so what is the cause of this disease that is killing more people?

So what are the health workers and CDF members doing about this AIDS?

What is the community's view about AIDS?

How do people treat those who are HIV-positive?

How does AIDS affect your house?

Do you sit down with your family members and talk about this disease?

What is your biggest worry about AIDS?

Does AIDS cause conflict in this household?

How do people treat those that are HIV positive?

How do family members treat those who are HIV positive?

Gogo [Grandmother], what are your beliefs about the causes of AIDS?

What are the consequences for those who are HIV positive?

What are the consequences towards the family members?

What is the impact of HIV/AIDS on the community?

What is the community doing to address the issue?

What are the results of negative reaction to the people who are positive?

What are the results of negative reactions towards the family members?

What is the difference between AIDS and Tindzhaka?

What is the attitude of people towards somebody with Tindzhaka, and how is it different from the attitude towards someone with HIV/AIDS.

Have you ever taken care of orphaned kids? Tell me what you were doing to take care of this child? What financial and social resources did you have to take care of the child?

Have you ever taken care of the sick? What did you experience in taking care of the sick?

How does care giving for the sick and grandchildren affect your health?

How is your health affected by what you do on a typical day?

How is your mental health?

How does care giving for the sick and your grandchildren affect your mental health?

How does your mental health affect what you done a typical day?

Do you have people with whom you can trust and talk to?

How difficult was it during the sickness, death funeral and mourning?

How did the mourning, illness and death affect the household financially?

As you know more people are dying everyday, especially the young ones, so what is the cause of this disease that is killing more people?

So what are the health workers and CDF members doing about this AIDS?

What is the community's view about AIDS? How do people treat those who are HIV-positive?

\section{References}

Ashfort, A., \& Nattrass, N. (2005). Ambiguities of 'culture' and the antiretroviral rollout in South Africa. Social Dynamics, 31, 285-303.

Benatar, S. R. (2004). Health care reform and the crisis of HIV and AIDS in South Africa. The New England Journal of Medicine, 351, 81-92.

Cameron, E. (2005). Witness to AIDS. Cape-Town: Tafelberg. 
Campbell, C., Foulis, C., Maimane, S., \& Sibiya, Z. (2005). "I have an evil child at my house": Stigma and HIV/AIDS Management in a South African Community. American Journal of Public Health, 95, 808815.

Castro, A., \& Farmer, P. (2005). Understanding and addressing AIDS-related stigma: from anthropological theory to clinical practice in Haiti. American Journal of Public Health, 95, 53-59.

Chimwaza, A., \& Watkins, S. (2004). Giving care to people with symptoms of AIDS in rural sub-Saharan Africa. AIDS Care, 16, 795-805.

Clark, S. J., Collinson, M. A., Kahn, K., Drullinger, K., \& Tollman, S. M. (2007). Returning home to die: circular labour migration and mortality in South Africa. Scandinavian Journal of Public Health, 35(3), 35-44.

Corbin, J., \& Strauss, A. (1990). Grounded theory research: procedures, canons and evaluative criteria". Qualitative Sociology, 13, 3-21.

Deacon, H., Stephney, I., \& Prosalendis, S. (2005) Understanding HIV/AIDS stigma: A theoretical and methodological analysis. Human Sciences Research Council Research Monograph, Pretoria, South Africa.

Duffy, L. (2005). Suffering, shame and silence: the stigma of HIV/AIDS. Journal of the Association of Nurses in AIDS Care, 16, 13-20.

Ferreira, M., Keikelame, M., \& Mosaval, Y. (2001) Older women as carers to children and grandchildren affected by AIDS: A study towards supporting the carers. Institute of Ageing in Africa, University of Cape Town, Cape Town, South Africa.

Gilbert, L. (2008). Public Health and Health Professionals in the times of HIV/AIDS. South African Sociological Review, 39, 302-317.

Gilbert, L., \& Walker, L. (2010). "My biggest fear was that people would reject me once they knew my status..."-Stigma as experienced by patients in an HIV/AIDS clinic in Johannesburg, South Africa. Health \& Social Care in the Community, 18, 139-146.

Goffman, E. (1963). Stigma: notes on the management of spoiled identity. New York: Simon and Schuster.

Knodel, J., \& Saengtienchai, C. (2002). AIDS and older persons: The view from Thailand, population studies center research report, No. 02-497. Michigan: Ann Arbor.

Liddell, C., Barrett, L., \& Bydawell, M. (2005). Indigenous representations of illness and AIDS in subSaharan Africa. Social Science and Medicine, 60, 691-700.

Madru, N. (2003). Stigma and HIV: does the social response affect the natural course of the epidemic. Journal of the Association of Nurse in AIDS Care, 14, 39-48.

Mahajan, A. P., Sayles, J. N., Patel, V. A., Remien, R. H., Sawires, S. R., Ortiz, D. J., et al. (2008). Stigma in the HIV/AIDS epidemic: a review of the literature and recommendations for the way forward. AIDS, 22 (Suppl 2), S67-S79.

McDonald, C., \& Schatz, E. (2006). Competing discourses: how older women in rural South Africa make sense of the HIV/AIDS epidemic, University of Colorado Population Program Working Paper, POP 2006-09.

Muyinda, H., Seeley, J., Pickering, H., \& Barton, T. (1997). Social aspects of AIDS-related stigma in rural Uganda. Health and Place, 3, 143-147.

Neuman, L. (2003). Social research methods: Qualitative and quantitative approaches. USA: Pearson Education, Inc.

Ogden, J., \& Nyblade, L. (2005). Common at its core: HIV-related stigma across contexts. International Center for Research on Women (ICRW).

Ogunmefun, C. (2008). The impacts of adult HIV/AIDS mortality on elderly women and their households in rural South Africa, a PhD thesis submitted to the Faculty of Humanities, University of Witwatersrand, Johannesburg, South Africa.

Ogunmefun, C., \& Schatz, E. (2009). Caregivers' sacrifices: the opportunity costs of adult morbidity and mortality for female pensioners in rural South Africa. Development Southern Africa, 26(1), 95109.

Oktay, J. (2004). Grounded theory. In D. Padgett (Ed.), The qualitative research experience. Belmont: Wadsworth/Thomson Learning.

Parker, R., \& Aggleton, P. (2003). HIV and AIDS-related stigma and discrimination: a conceptual framework and implications for action. Social Science \& Medicine, 57, 13-24.

Patton M. (1990). Qualitative evaluation and research methods, 2nd edn. Newbury Park, London, New Delhi: Sage Publications.

Poindexter, C., \& Linsk, L. (1999). HIV-related stigma in a sample of HIV-affected older female African American Caregivers". Social Work, 44, 46-61.

Posel D. (2004). Sex, death and embodiment: reflections on the stigma of AIDS in Agincourt, South Africa, a paper for symposium on life and death in a time of AIDS: the Southern African experience, Wits Institute for Social and Economic Research (WISER), 14th-16th October, 2004. 
Reid, G., \& Walker, L. (2003). Secrecy, stigma and HIV/AIDS: an introduction. African Journal of AIDS Research, 2, 85-88.

Saengtienchai, C., \& Knodel, J. (2001). Parental caregiving to adult children with AIDS: A qualitative analysis of circumstances and consequences in Thailand. Population studies center research report, No. 01-481. Michigan: Ann Arbor.

Scambler, G. (2004). Re-framing stigma: felt and enacted stigma and challenges to the sociology of chronic and disabling conditions. Social Theory \& Health, 2, 29-46.

Scambler, G. (2006). Sociology, social structure and health-related stigma. Psychology, Health \& Medicine, $11,288-295$.

Schatz, E. (2007). Taking care of my own blood: older women's relationships to their households in rural South Africa. Scandinavian Journal of Public Health, 35(4), 147-154.

Schatz, E. (2009). Reframing vulnerability: mozambican refugees' access to state-funded pensions in rural South Africa. Journal of Cross-Cultural Gerontology, 24(3), 241-258.

Schatz, E., \& Ogunmefun, C. (2007). Caring and contributing: the role of older women in multi-generational households in the HIV/AIDS era. World Development, 35(8), 1390-1403.

Simbayi, L. C., Kalichman, S., Strebel, A., Cloete, A., Henda, N., \& Mqeketo, A. (2007). Internalised stigma, discrimination and depression among men and women living with HIV/AIDS in Cape Town, South Africa. Social Science \& Medicine, 64, 1823-1831.

Steinberg, J. (2008). Three-Letter plague. Johannesburg: Jonathan Ball Publishers.

Squire, C. (2007). HIV in South Africa. Johannesburg: Routledge.

UNAIDS. 2000. HIV and AIDS-related stigmatization, discrimination and denial: forms, contexts and determinants. Joint United Nations Programme on HIV/AIDS (UNAIDS).

VanLandingham, M., Im-em, W., \& Saengtienchai, C. (2005) Community reaction to persons with HIV/ AIDS and their parents in Thailand. Population studies center research report, No. 05-577. Ann Arbor: Michigan.

Walker, L. (2007). HIV/AIDS; Challenging stigma by association. In P. Burke \& J. Parker (Eds.), Social work and disadvantage (pp. 79-96). London: Jessica Kingsley Publishers.

World Health Organization (WHO) (2002) Impact of AIDS on older people in Africa: Zimbabwe case study, World Health Organisation Report. WHO, Switzerland.

Yang, L. H., Kleinman, A., Link, B. G., Phelan, J. C., Lee, S., \& Good, B. (2007). Culture and stigma: adding moral experience to stigma theory. Social Science \& Medicine, 64, 1524-1535.

Zhou, Y. R. (2007). If you get AIDS... You have to endure it alone: understanding the social constructions of HIV/AIDS in China. Social Science and Medicine, 65, 284-295. 